\title{
Growth of Muslim Community as Minority in India
}

\author{
Preeti Yadav, Samra Sultana
}

\begin{abstract}
The Encyclopedia of Britannica minority means "group held together by ties of common descent, language or religious faith and feeling different in these respects from the inhabitants of a given political entity." This study be related about minorities, especially Muslim community, their constitutional rights and safeguards, socio-economic conditions and other safeguards like welfare Programs and various government reports and commissions, including Minority Ministry in India. This study is important because it details the legal definition, rules and regulations and the other terms related to the discussion of minority. This paper is an attempt to showcase the relationship between minority development policies and satisfaction to the community.
\end{abstract}

Keywords: Minority, Welfare, Socio Economic Conditions, etc.

\section{INTRODUCTION:}

A group which is numerically inferior from the rest of the State will be in a non-dominant state, and whose population will national of the State. The population will have features related to ethnic, religious or linguistic which will be different from the rest of the population of the area and will exhibit solidarity and preservation of their culture, traditions, religion and languages.

The non-dominant groups put in all the efforts to protect their cultural, religious and ethnic differences which came up as the result of creation of nation states in the 18 and 19 centuries. This protection of international law related to minority section started by the League of Nations with the adoption of the "minority treaties". In 1945 the United Nations replaced the League of Nations and made new norms, rules and regulations, procedures related to minority section. The word "minority" comes from a word of Latin meaning "minor" and the suffix of 'ity' means "small in number".

The United Nations Declaration on the Rights of Persons related to National, Ethnic, Religious and Linguistic Minorities states that preservation of the rights of people of minority sector contributes in the political and social stability of their economies. The protection of their dignity reduces the stress of these groups which leads to stability and peace. Thus, whether developed countries or developing, countries do give importance to their welfare.

Revised Manuscript Received on November 11, 2019.

Dr. Preeti Yadav, Associate Professor, Amity Business School, Amity University, Jaipur.

Samra Sultana, Research Scholar, Amity Business School, Amity University, Jaipur.
* Correspondence Author

\section{MINORITY CLASS OF INDIA:}

Indian constitution describes 'minority' as a group of people having less than half of the population and differs from others with respect to their race, religional background, traditional approach, cultural history and the usage of language.

Indian economy considers the people minorities who follows any other religion except Hindu at the national level as 80 percent of the Indian population professes Hindu as their religion. At the national level, Muslims have the largest minority as other minorities are much smaller in size as compared to Muslims in India. Muslims with respect to minorities are followed by the Christians and Sikhs. Considering the language aspect, no majority can be found at the national level as per linguistic minorities and so the minority status is determined at the State level or Union Territory level. At the State level or Union Territory level in India - the Muslims class are seen to be in the majority number in the State of Jammu and Kashmir and in the Union Territory of Lakshadweep. Other states like Meghalaya, Mizoram and Nagaland, have Christians in the majority while Sikh community forms the majority community in Punjab. It is clear that no other religious class of the minorities is a majority in any State level or Union Territory level. The provision of 1993, the Central Government of India considered the below given communities to be "minorities" for this Act:
1. Muslim
2. Christians
3. Sikh
4. Buddhist and
5. Parsi (Zoroastrian)

\section{CONSTITUTIONAL RIGHTS FOR MINORITIES IN INDIA}

Indian economy has a lot of cast different communities, language, religion etc. Education plays a greater role in the Indian economy for the upliftment and betterment of the illiterate and below poverty line people.

It should be clear that the Constitution of India never discriminates its citizens on the basis of their creed, race, caste or any other ground and this should be kept in mind that the Articles of 25 to 30 of Indian Constitution are referred as Fundamental Rights and gives each and every citizen fundamental rights compulsorily under the Government of India. 
The remedies available to the citizens of India if their fundamental rights are violated are given the Articles of 30 and 226 of the Indian Constitution which states that if fundamental rights of any person are violated, he/she can directly approach the Supreme Court and the High Court of the Indian economy. Thus, it becomes clear that the aim of the Constitution of India is to safeguard the interest of the minorities. Apart from these, there some special articles also in the Constitution of India which are rendered to the minority class, which are as follows-

\section{EQUALITY BEFORE LAW}

The article 14 of India Constitution gives right related to the equality before the law and legislation of the nation.

Article 15 of the Indian Constitution allows the State to make "any special provisions" for women and children, "any socially and educationally backward class of citizens" and Scheduled Castes and Scheduled Tribes along with giving the State the power to make some special provisions for appointing candidates from socially and educationally backward classes or candidates belonging to Scheduled Castes/Tribes in any educational institutions of private educational institutions which might be aided or unaided by the State, other than minority educational institutions. Article 16 allows the State to make provisions in regards to the reservation in appointments "any backward class of citizens which, in the opinion of the State, is not adequately represented in the services under the State". Article 21_of the Indian Constitution states that No citizen of India can be denied of protection related to life or personal liberty.

\section{Exclusive Rights of Minorities}

Cultural Rights (Articles 29-30): Cultural \& Educational Rights to the minorities are mentioned in Articles 29 and 30 of the Indian Constitution. It includes the rights of:

- A citizens to preserve their lingo, writing or civilization;

- All religious and linguistic minorities to set up learning \& educational institutions of their preference;

- An educational institution set up next to the prejudice by State in the subject of State aid

- Citizen against the refusal of the appointment in State-maintained or State-aided educational institution.

\section{Planned Development of Minorities (with special reference to Muslim community)}

Studies and census 2001 on Muslim class showed that they are educationally backward, which was an eye opener for policy makers and the implementers.

\section{Statutory National Commission for Minority}

Statutory National Commission was formed in 1993 by the Ministry of Welfare, Government of India on which five communities were considered as minority communities which are listed with their details:

\begin{tabular}{|c|c|r|c|}
\hline $\begin{array}{c}\text { Minority } \\
\text { Community }\end{array}$ & $\begin{array}{c}\text { Number in } \\
\text { Crores }\end{array}$ & \multicolumn{1}{c|}{ Number } & $\%$ \\
\hline Muslim & 17.22 Crores & $172,245,158.00$ & 14.23 \\
\hline Christian & 2.78 Crores & $27,819,588.00$ & 2.30 \\
\hline Sikh & 2.08 Crores & $20,833,116.00$ & 1.72 \\
\hline Buddhist & 84.43 Lakhs & $8,442,972.00$ & 0.70 \\
\hline Parsi & Less than Lakh & $57,264.00$ & 0.00 \\
\hline Total & & $\mathbf{2 2 9 , 3 9 8 , 0 9 8 . 0 0}$ & 18.95 \\
\hline
\end{tabular}

Functions of the commission

- Evaluating the improvement \& development of minorities in the Nation;

- Monitoring the operational and functional related matters to the safeguards for minorities;

- Making recommendations for the effective implementation of safety keys related to the safeguards of the benefit and welfare of minorities

- $\quad$ Seeing the complaints of deprivation of rights and protective measures of minorities

- Studies related to the problems unfairness against them

- $\quad$ Signifying suitable ways for any minority classes undertaken by the Goverment

- Any other matter given to it by the Central Government.

Economic and Educational Status of Muslim Community in India (Sachar Committee)

Committee on social, economic and educational Status of Muslim community in India was formed in 2005 having Justice Rajinder Sachar as its chairman by the Prime Minister. Its report was submitted in November, 2006. The committee concerns with socio-economic status, poverty status, low literacy and educational level, higher unemployment rates, infrastructure level.

\section{Ministry of Minority Affairs}

In 2006, Ministry of Minority Affairs was formed to provide focused approach for issues concerned with minorities and facilitatation of the formulation of various policies and planning, dexterity, assessment and review of the authoritarian framework and development of the minority class. The Ministry of Minority Affairs also looks after minority communities apart from matters concerning to law and order.

\section{THE NATIONAL COMMISSION FOR RELIGIOUS AND LINGUISTIC MINORITIES [NCRLM]}

The NCRLM was formed in 2004 under the chairmanship of Chief Justice of India Justice- Mr Ranganath Misra. The commission submitted its report to the Indian Government in 2007 with conditions of reference mentioned below- :

(a) Telling criteria related to recognition of socially and economically weaker sections of religious and linguistic minorities; 
(b) Recommending steps for the welfare of socially and economically backward classes of religious and linguistic minorities which includes reservation in the jobs

(c) Suggesting about needed lawful, permissible and administrative modalities or the implementation of its recommendations.

Government of India increased in the resources for minorities in the budget in the last three years which is given below-

\begin{tabular}{|c|c|r|r|}
\hline \multicolumn{4}{|c|}{ Ministry of Minority Affairs fund allocation } \\
\hline Five Year Plan & \multicolumn{1}{c|}{ Year } & \multicolumn{1}{c|}{ RS. In Crore } & \multicolumn{1}{c|}{ Average / Year } \\
\hline 11th Plan & $2007-2012$ & $7,000.00$ & $1,400.00$ \\
\hline 12th Plan & $2012-17$ & $17,323.00$ & $3,464.60$ \\
\hline & $2017-18$ & $4,195.48$ & $4,195.48$ \\
\hline & $2018-19$ & $4,700.00$ & $4,700.00$ \\
\hline
\end{tabular}

Source: 11 th \& 12 th plan \& Annual Report MOMA

Source:pibarchive.nic.in/ndagov/Comprehensive-Materials/compr26.pdf (National Minority

Commission Report)

For the socio-economic development and welfare of deprived minorities, apart from PM New 15 PP Schemes, the government focuses on some direct intervention schemes through Minority Ministry, which may be divided into three categories:

1. Educational Empowerment

2. Area Development

3. Economic Empowerment

\section{Educational Empowerment}

\section{Scholarship}

About 5 crore, 29 lakhs $(52,985,413)$ minority beneficiaries have availed scholarship amounting Rs. 11,570 crore since inception of scholarship scheme, from 2007-08 to 2017-18. Under scholarship scheme, the Ministry has been implementing the following three types of Scholarships plans in the eleventh Five Year Plan.

- Plan related to Pre-Matric Scholarship

- Plan related to Post-Matric Scholarship

- Plan related to Merit-cum-means Based Scholarship

\section{MAULANA AZAD NATIONAL FELLOWSHIP (MANF)}

MANF scholarship was come in existence in year 2009-10 to give fellowship of five years to do research students in the various universities and institutions recognized by UGC. This scheme is implemented through UGC and the fellowship is in the pattern of UGC fellowships. The rate of fellowship and eligibility conditions for students are at par with those of UGC fellows. To obtain this fellowship, the candidate student should have a minimum score of $50 \%$ at the PG level. Under this scheme every year 756 fresh scholars are selected for the fellowship in addition to the renewal of fellowship for scholars selected during previous years.

Fellowship: Rs. 25000/- per month for the starting two years (JRF) and Rs. 28000/- per month. for the rest of time.
Physical and financial achievements

\begin{tabular}{|c|c|c|c|c|}
\hline \multicolumn{5}{|c|}{ MANF } \\
\hline 2018-19 & \multicolumn{3}{|c|}{ Budget Allocation (Rs in Crore) } & 153 \\
\hline \multirow{3}{*}{ Financial Year } & \multicolumn{4}{|c|}{ Acheivements } \\
\hline & \multicolumn{3}{|c|}{ No of Fellowship distributed } & \multirow{2}{*}{$\begin{array}{c}\text { Amount (Rs. In } \\
\text { Crore) }\end{array}$} \\
\hline & Fresh & Renewal & Total & \\
\hline $2009-10$ & 757 & & 757 & 14.90 \\
\hline $2010-11$ & 754 & 577 & 1,331 & 29.98 \\
\hline 2011-12 (Budget) & 755 & 1511 & 2,266 & 52.00 \\
\hline 2013-14 & 756 & 756 & 1,512 & 50.02 \\
\hline 2014-15 & & & 4,532 & 0.02 \\
\hline $2015-16$ & & & 5,288 & 55.52 \\
\hline $2016-17$ & & & 6,044 & 119.92 \\
\hline \multicolumn{3}{|c|}{ Total } & 21,730 & 322.36 \\
\hline
\end{tabular}

\section{NAI UDAAN}

It is a plan to Support Minority Students for qualifications of Prelims which are conducted by UPSC/SSC/State PSCs. Maulana Azad Education Foundation

The Foundation operates its schemes from the interest received from Corpus Fund being its one and only way to earn income and as part of assistance. The Corpus Fund was of Rs.100 crores in 2006-07 and currently of Rs. 700.00 crore. It is expected to be Rs. 750 crores by the end of the $11^{\text {th }}$ Plan.

\section{Income (main) is Interest earned on its Corpus Fund}

2006-07: Corpus of Rs.100 cr.

\section{Plan: Rs $550 \mathrm{Cr}$ added in Corpus}

XII Plan Target: Corpus of Rs. $1250 \mathrm{Cr}$.

\section{Area Development Programme}

\section{PRADHAN MANTRI JAN VIKAS KARYAKRAM}

The year 1987 witnessed the preparing of the list containing 41 minority concentration districts which was based on the information of Census, 1971. Identification of such 41 minority concentration districts depended on the fact that the population of these should be 20 percent or more in a district. A fresh exercise was carried out in 2007-08 based on population data and backwardness parameters of Census 2001. This resulted in the identification of 90 minority concentration districts with the approval of the Cabinet on $17^{\text {th }}$ May, 2007.

These districts were not only having a substantial minority population, but were also backward, many with unacceptably low economic or amenities indicators, and in urgent need of focused development.

\section{COVERAGE AREA OF THE PLAN}

* To fill the loopholes of currently central sponsored plans of Indian government which was implemented by several Central Ministries and departments

* To implement the non gap filling plans for the upgradation of the minority section

The plan was implemented in the year 2013 to 14 with making some changes in structure which are as follows-

* the Minority Concentration Districts were taken over by the Minority Concentration Blocks which were 710 in number 
* the set up of new Minority Construction Towns

* the setup of Minority Concentration Villages under the scheme

* Minority Concentration Blocks with a minimum of $25 \%$ population with belongs to minority section were identified

\section{MINORITY CONCENTRATION TOWNS}

Minority Concentration Town is the towns which are being found in the MCB backward regions. Additionally, -

* the towns which were backward with regards to the social and economic status and lack of basic amenities were found * the towns which fulfills the above mentioned criteria but fails in the 90 MCD's were not included

\section{ASPECTS RELATED TO CLUSTER OF VILLAGES}

Identification of cluster of villages as follows-

* The Backward Minority Concentration Villages which had population of $50 \%$ from minority sector was excluded from MCB

* 13 type of clusters were found which included in Manipur, Tripura and Meghalaya

\section{8-19}

- In the previous Financial Year, the plan was restructured by the confir,mation of the Cabinet in May, 2018.

- The plan was restructured and given new name that is "Pradhan Mantri Jan Vikas Karyakram" (PMJVK)

- The objective was to make sure that gains from the plans should have access to more people and help them solve their problems related to women section, children population, the students and youth population

\section{- Salient Features of PMJVK}

\section{Earmarking of resources}

- About 80 percent of available resources were for areas like Education, Skill and Health.

- About 33-40 percent of the above has to be spent on women related plans.

\section{ELIGIBLE AREAS EXTENSION}

- Inclusion of Minority Concentration District Headquarters.

- Census, 2011 identified Area related to PMJKV

\section{SEEKHO AUR KAMAO SCHEME}

Seekho aur kamao scheme is a skill development scheme which is meant for minorities. The plan was started in the year 2013-14 among the minority population. The program has the objective to develop the skills of the youth of the minority section. These skills are related to modern or traditional skills which depend on the qualifications, the current economic status, market conditions etc which can give employment to the youth of the minority sector and provide them with self employment. The Eligible trainees for program are as follows-

* the trainees Should be from minority sector

* the trainees should be of age group of 14 to 45 years

* the trainees should have the minimum qualification of class $5^{\text {th }}$

\section{REVIEW OF LITERATURE:}

Rahman Azimur, Khatoon Naseema, Pathak Vinay Kumar, Mohammad Ali Imam (2014), in their paper main focus was on Muslim women on parameters like their education, social status, their participation in political system, role in family planning. Basically it's about the gender equality in the country like India. To explore these aspects both quantitative and qualitative methods are used. This study was done on Muslim women of Azamgarh District which is in Uttar Pradesh of India. The sample size was 365 Muslim women. The objective of study was education of Muslim women, their participation in family planning and political participation. Khan \& Shyed (2013) showcased the situation of middle class educated Muslim families. In this study the main focus was on female respondents. He concludes that Muslim female have to go with the culture, religious jobs even they may be high education. This shows that the conditions of females are not changing with change in policies and education level.

Amanda.et.al (2011) expressed her view about religion and ethnicity with study of three Muslim females. She found that a big gap between fantasy and real life of minor women. As per her paper a sustainable process is required for development of Muslim women.

Nayyar (2007), she observed in her study that, it's been long time we got independence but still women in India facing lots of challenges, especially Muslim women. Muslims in India constitutes the major minority in the world after Indonesia. Muslim women are far behind Muslim male if we compare it with other religion. In every family woman play a vital role in every situations and stage of life. Gender inequality can be seen all aspects like lack of education, discrimination, family planning, choice of marriage, opportunities to work, etc. They are still bounded by family expectations and restricted to that only. It's not only in some parts of the country, but can be seen in every different region, in all class, religion and caste. Government need to identify parameters and should make provisions and policies to rectify these discriminations. Muslim women status can be increased by focusing on the parameters like their economic and social conditions, improvement in education.

After the study of various research papers, researcher found that most of the studies are concerned with Muslim females only. There is requirement of vast level study on whole community. So researcher found a gap for this paper.

Objective of the study: To assess the level of growth of Muslim community in India.

On the basis of above mention objective researcher have developed the following hypothesis:

Ho: There is no significant impact of various developmental policies on socio-economic conditions of Muslim Community.

Ha: There is a significant impact of various developmental policies on socio-economic conditions of Muslim Community. 


\section{ANALYSIS \& FINDINGS:}

Researcher has collected data from local Muslim community members of Rajasthan by convenient sampling method. The sample size is 200 respondents out of which 50 were female and 150 were male. This gender difference shows the dominance of male in community. The education level of respondents is quite justified as because most of the respondents were graduate and post graduate. To test the hypothesis researcher has used correlation methodology. Below given tables is presenting testing of hypothesis

Descriptive Statistics
\begin{tabular}{|l|r|r|r|}
\hline & Mean & Std. Deviation & N \\
\hline Awareness of Developmental Policies & 3.5950 & .50433 & 200 \\
Socio Economic Condition of Muslim & 4.0804 & .28507 & 200 \\
\hline
\end{tabular}

\begin{tabular}{|ll|r|r|}
\hline & Correlations & \multicolumn{1}{c|}{$\begin{array}{c}\text { Awareness of } \\
\text { Developmental } \\
\text { Policies }\end{array}$} & $\begin{array}{c}\text { Socio Economic } \\
\text { Condition of } \\
\text { Muslim }\end{array}$ \\
\hline \multirow{3}{*}{ Awareness of Developmental Policies } & Pearson Correlation & 1 & $.300^{* *}$ \\
& Sig. (2-tailed) & 200 & .000 \\
& $\mathrm{~N}$ & $.300^{* * *}$ & 200 \\
Socio Economic Condition of Muslim & Pearson Correlation & .000 & 1 \\
& Sig. (2-tailed) & 200 & 200 \\
\hline **. Correlation is significant at the 0.01 level (2-tailed). & &
\end{tabular}

In this result table, there is a positive correlation between awareness of developmental policies and socio-economic condition of Muslim Community. Here the researcher found co-relation $\mathrm{r}=.3$ with $\mathrm{p}=0.01$, so there is a positive correlation between awareness of developmental policies and socio-economic conditions of Muslim Community. Hence the null hypothesis is rejected and alternative hypothesis is accepted. On the end it can be conclude that government have worked a lot in case of minority upliftment which have positive impacts also but still some focused plan and policies are required for achieving the required growth level of Muslim community in India.

\section{REFERENCES:}

1. MOMA website, AR \& $12^{\text {th }}$ Plan, WG Report

2. Rahman Azimur, Khatoon Naseema, Pathak Vinay Kumar, Mohammad Ali Imam (2014), Comparative Study of Muslim Women's Education in the Context of employment, access to media, marital status, family planning and political participation - Case Study of Azamgarh District Fauzia Islam, IOSR Journal Of Humanities And Social Science (IOSR-JHSS) Volume 19, Issue 3, Ver. II (Mar. 2014), PP 186-196 e-ISSN: 2279-0837, p-ISSN: 2279-0845.

3. Khan, Shabnam Syed. (2013) Muslim Women and Tensions of Traditional, Modern Expectations. Harvard University, 2013.

4. Keddie, Amanda (2011). Framing discourses of possibility and constraint in the empowerment of Muslim girls: issues of religion, race, ethnicity and culture. Religion, Race and Ethnicity. Ethnicity and Education, 2011

5. Nayyar Usha (2007), An analytical study of education of Muslim women and girls in India, thesis, University of Delhi.

6. 11th \&12th plan, WG \& Steering Committee Report

7. Annual Report MOMA, pibarchive.nic.in/ndagov/Comprehensive-Materials/compr26.pdf

8. www.seekhoaurkamao-moma.gov.in 